\title{
The Effect of Stirring Rate on Electrodeposition of Nanocrystalline Nickel Coatings and their Corrosion Behaviors and Mechanical Characteristics
}

\author{
Kaveh Rahimi Mamaghani, Seyed Morteza Naghib* \\ Department of Nanotechnology, School of New Technologies, Iran University of Science and \\ Technology (IUST), Tehran, Iran \\ *E-mail: Naghib@iust.ac.ir
}

doi: $10.20964 / 2017.06 .68$

Received: 25 February 2017 / Accepted: 19 April 2017 / Published: 12 May 2017

\begin{abstract}
Nanocrystalline pure nickel coating was electroplated on pure copper by means of a modified Watts bath with variant stirring rates and current densities. The crystallite sizes were calculated by XRD analysis. The crystallite size had an inverse relation with stirring rate and current density in the plating bath. The best corrosion resistance was observed in $5 \mathrm{~A} / \mathrm{dm}^{2}$ current density of polarization test and corrosion rate smoothly increased by agitation in the plating bath. The microstructure evolution at high stirring rates exhibited some surface bubbles that affected the surface quality and properties. Although Vickers microhardness increased by the addition of the current density, our measurements showed that the hardness had an inverse relationship with turbulence in the solution. An optimum agitation in the bath could improve the hardness distribution on the coated specimen. However, specimens with agitation did not follow the Hall-Petch relationship between crystallite size and microhardness.
\end{abstract}

Keywords: Nanocrystalline nickel; Electrodeposition; Stirring rate; Corrosion; Hardness.

\section{FULL TEXT}

(C) 2017 The Authors. Published by ESG (www.electrochemsci.org). This article is an open access article distributed under the terms and conditions of the Creative Commons Attribution license (http://creativecommons.org/licenses/by/4.0/). 